\title{
A HISTÓRIA COMO CRÍTICA DO PRESENTE: O CONCEITO DE HISTÓRIA COMO INSUMO DA CIÊNCIA POLITTICA EM EDMUND BURKE E ALEXIS DE TOCQUEVILLE
}

\section{Helio Cannone ${ }^{1}$}

\section{RESUMO}

Este trabalho pretende-se uma análise comparativa do uso da História para compreensão da política em Edmund Burke e em Alexis de Tocqueville, a partir das respectivas obras de crítica a revolução francesa dos autores. A hipótese que se busca justificar é que os dois se encontram entre um conceito de História como mestra da vida e uma filosofia da História moderna, que comporta em si a ideia de aperfeiçoamento.

Palavras-chave: história e política, teoria política moderna, conceito de história, revolução francesa

\section{HISTORY AS A CRITICS OF THE PRESENT: THE HISTORY CONCEPT AS IMPUT OF POLITICAL SCIENCE AT THE WORK OF EDMUND BURKE AND ALEXIS TOCQUEVILLE}

\section{ABSTRACT}

This papper intends to do a comparative analysis of use of the concept of history to understand the politics in the work of Edmund Burke and Alexis Tocqueville. Each one of the authors have books that pretends to analysis the French revolution. The hypotheses of this papper is that both of the authors are between a history concept as magistra vitae and as a philosophy of history that comport the ideia of improvement.

Key-words: history and politics, modern political theory, concept of history, French revolution

${ }^{1}$ Helio Cannone é graduado em História com Bacharelado e Licenciatura pela PUC-Rio e Mestre em Ciência Política pelo IESP-UERJ, onde atualmente é Doutorando em Ciência Política. helio.cannone@ gmail.com 
Introdução²

Este trabalho pretende explorar o uso do conceito de história para a compreensão da política a partir das obras de crítica à Revolução Francesa Reflexões sobre a Revolução na França de Edmund Burke (2014) e O Antigo Regime e a Revolução de Alexis de Tocqueville (2009). A hipótese que aqui busca-se demonstraréque ambos os autores fazemuso da história como insumo necessário tanto para a análise quanto para a ação política, apesar de ora convergirem sobre a semântica e o uso do conceito e ora não. Para tal estudo será feito o itinerário de apresentação e análise das respectivas obras respeitando sua sequência cronológica.

Como aporte teórico serão usadas as obras Regimes de Historicidade de François Hartog (2013) e O conceito de História, organizada por Koselleck, Meier, Gunther e Engels (2013). A partir destes autores se tem a intenção de analisar a relação entre história e política em Burke e Tocqueville levando em conta os regimes de historicidade predominantes na época em que escreveram. Com isso é possível situá-los entre um conceito de História enquanto mestra da vida e de uma filosofia da história que leva em conta o aperfeiçoamento dos homens a partir de certa concepção de progresso.

Por fim, nas considerações finais deste trabalho, pretende-se apresentar através de obra de François Furret como a historiografia revisionista da revolução francesa elaborada na segunda metade do século XX se apropriou da tradição crítica deixada por Edmund Burke e Tocqueville. Tal autor parte principalmente de Tocqueville para combater as intepretações hegemônicas de sua época da revolução francesa ao mesmo tempo que acaba por trazer as ideias políticas de volta para discussão historiográfica, então majoritariamente econômica e social.

\section{Edmund Burke e a História entre a tradição e o aperfeiçoamento}

Segundo apresenta François Hartog (2013), a ideia de que a história serve como mestra da moral remete ao pensador romano Cícero. Não à toa que essa figura é da mais citadas por Edmund Burke. De fato, é possível observar em suas Reflexões sobre a revolução na França (BURKE, 2014) o uso da história

2 Este trabalho foi melhorado pelas contribuições do professor Paulo Henrique Cassimiro, ao qual o autor é grato. Contudo, qualquer erro aqui cometido é de inteira responsabilidade do autor.

CSOnline - Revista Eletrônica de Ciências Sociais, Juiz de Fora, n. 27 (2018) 
como mestra da vida. Tal concepção entende a história como algo que os homens no presente devem usar para orientar sua ação, uma vez que ela carrega em si os feitos de personagens que souberam agir com prudência em momentos decisivos. Do mesmo modo, tal conceituação de história pode apresentar exemplos pela negativa, ao demonstrar como não se deve agir em determinada situação de acordo com os erros cometidos em experiências passadas. Segundo Horst Gunther (KOSELLECK et al, 2013) isso só é possível pois os autores compreendem a natureza humana como fixa ou pouco mutável, assim, as mesmas condutas possibilitariam as mesmas consequências. Se o homem não teria mudado substancialmente no decorrer do tempo, cabe recorrer aos grandes exemplos deixados pela antiguidade para se tornar um ser virtuoso no agir do presente.

A obra de Edmund Burke foi escrita originalmente em 1790 como uma carta a um fidalgo francês sobre os acontecimentos que estavam em curso no país. Partindo de um entendimento de história como de caráter exemplar, o autor irá formular sua crítica àsse Revolução francesa a partir da defesa do uso das experiências acumuladas na história em detrimento da pura abstração no fazer político. Crítico a qualquer ideia de tábula rasa, ele defende que as mudanças que se faziam necessárias na França do Antigo Regime poderiam ter sido resolvidas sem o recurso à violência, com reformas demoradas no tempo e que levassem em conta as tradições acumuladas historicamente por aquela nação. $\bigcirc$ exemplo a ser seguido seria a própria revolução da Inglaterra em 1688. Para tal, o autor faz muito uso de exemplos históricos. Eles parecem cumprir tanto a função de analogias para comprovar a sua defesa da tradição e do caráter exemplar das experiências passadas, quanto de artifícios literários. Burke usa não só exemplos da própria Inglaterra, mas também da história de Roma Antiga. Ele parece mesmo partir de uma ideia de natureza humana comum e de uma concepção de história como mestra da vida, uma vez que usa a história tanto para compreender a natureza dos homens quanto para orientar sua ação no presente e no futuro.

O conceito de revolução de Burke parece estar em consonância com o que Hannah Arendt (2011) apresenta como o conceito antigo de revolução. Em tal definição, a revolução seria uma volta ao estado original das coisas, a manutenção de certa ordem que foi ameaçada por algo externo a ela. A ação dos homens serve então para preservar suas instituições e toda alteração é feita apenas nesse sentido. Na mesma chave, é possível afirmar que a crítica de Burke as movimentações políticas da França em sua época têm a ver com o fato de estes 
atores operarem com o que Arendt (Idem) classifica como conceito moderno de revolução, na qual os indivíduos agem para alterar o mundo tal como ele se apresenta a partir de uma ideia de linearidade histórica.

No decorrer do texto o autor se ocupa de refutar as reivindicações da Sociedade da Revolução, grupo inglês simpático a Revolução Francesa. A primeira diz respeito a legitimidade do Rei se basear no povo. Para Burke não era concebível a ideia de soberania do povo defendida por tal grupo. O rei da Inglaterra não era legitimo na medida em que foi escolhido por seu povo. É na história da Inglaterra que Burke vai investigar a origem das leis de sucessão e de legitimidade real para se opor a tal hipótese. Ele explica que os princípios da Revolução de 1688 estariam na Declaração de Direitos. A partir de tal documento o parlamento teria estabelecido quem deveria herdar a coroa, uma vez que existiria a possibilidade do Rei Guilherme não deixar descendentes. O argumento de porquê estabelecer com precisão a linhagem não se baseava em soberania popular, mas garantia de segurança e estabilidade no reino.

Para Burke, as leis e a Constituição de uma nação não têm sua origem em preceitos abstratos, mas no agir prudencial para resolver uma necessidade dada em determinada situação, fato observável no passado. Ele recorre a experiência histórica para compreensão da política e para proposição dos caminhos que devem ser seguidos na mesma, como espécie de arma contra idealismos:

Se o senhor desejar conhecer o espírito de nossa Constituição e a política predominante que garantiu até os nossos dias, procure-os em nossas histórias, em nossos arquivos, em nossas leis e diários do Parlamento, e não nos sermões da Old Jewry, ou nos brindes de sobremesa da Sociedade da Revolução: no primeiro, o senhor encontrará outras ideias e outra linguagem. (BURKE, 2014, p. 52)

De forma coerente ao seu pensamento e sua concepção de história, o autor defende a manutenção dos costumes e faz uso de uns topos que Mannheim (1981) explica ser comum ao conservadorismo político moderno: a ideia de que as transformações precisam vir aos poucos e baseadas em antecedentes históricos que valorizem a tradição:

A simples ideia de criar um novo governo é suficiente para encher-nos de repulsa e horror. Na época da Revolução, como na atual, o que desejávamos 
era derivar tudo o que temos como uma herança de nossos antepassados. [...] Todas as reformas que fizemos até hoje respeitaram o princípio de referência ao passado; e espero, ou melhor, estou convencido de que todas as que possamos realizar no futuro estejam cuidadosamente construídas sobre precedente, autoridade e exemplos análogos. (BURKE, 2014, p. 53)

Burke ilustra tal afirmação com exemplos de documentos da História da Inglaterra: Magna Carta, Petição de Direitos e Declaração de Direitos. A liberdade vivida em seu tempo é para Burke herança inalienável deixada pelos antepassados, sempre em referência a algum direito anterior.

A segunda reivindicação da Sociedade da Revolução criticada pelo autor diz respeito ao direito de destituir os governantes por má conduta. Edmund Burke também irá se opor a ela. Seu argumento é de que o rei só pode ser compreendido como servidor do povo no sentido de que o fim racional do seu poder é o bem geral. Contudo, em outro sentido, como aquele que tem que obedecer a ordens, o rei não o é. A função de rei tem como inerente ao cargo que quem o ocupa não obedece a ninguém e deve ser obedecido por todos dentro do seu reino. Por isso, o rei não poderia ser facilmente destituído pela vontade de outros. Depor um rei seria um caso extraordinário, geralmente alheio ao direito. A deposição dos reis que a Sociedade da Revolução defende dificilmente poderia ser executada sem violência. Recorrendo a lei como o critério pelo qual a história vai se sedimentando no presente, Burke argumenta que:

Nossa Constituição não conhece uma magistratura semelhante à da Justicia de Aragón, nenhum tribunal legalmente constituído ou procedimento legalmente estabelecido que possa submeter o rei à responsabilidade que cabe a todos os servidores. (BURKE, 2014, p. 51)

A aposta na via inglesa também parte do entendimento do autor de haver na Inglaterra simetria entre sociedade civil e Estado. Fórmula esta que para ele seria ideal, uma vez que demonstra o ajuste das instituições com a tradição e os costumes do pais. A crítica ao idealismo francês aparece também na obra do autor através da crítica à tentativa de construir as políticas de modo como se no país não houvesse sociedade civil e como se o povo francês não tivesse uma história e uma tradição. O resultado desse desencaixe seria a decadência econômica do país, povo empobrecido, igreja saqueadas e uso de violência como 
ferramenta de transformação da política. A Assembleia geral da França teria não só desrespeitado a tradição em sua composição como teria priorizado o idealismo e a inexperiência. Ela teria sido feita em maior parte por advogados profissionais que implementavam mecânicas, e não de magistrados distintos de notória ciência, prudência e integridade para assuntos do Estado.

Segundo Gunther, a concepção de história como mestra da vida possuiria "[...]a capacidade junto com a Ética, de estar subordinada à Ciência Política. " (KOSELLECK et al, p. 112). Tal relação entre política e história parece estar presente em Burke uma vez que ele entende que a Ciência do governo é uma ciência prática e deve ser pensada pelos propósitos práticos e não a partir de abstrações. Por isso a política deve ser feita com cautela e sem desprezar as experiências e os acúmulos deixados pela história:

Sendo, portanto, a ciência do governo tão prática em si mesma e destinada a esses propósitos igualmente práticos; sendo uma matéria que requer uma experiência superior à que alguém consegue obter no transcurso de sua vida, por mais sagaz e observador, é com infinita cautela, portanto, que se deve aventurar a derrubar um edifício que durante séculos vem respondendo razoavelmente bem aos propósitos comuns da sociedade, ou a edifica-lo novamente sem ter em vista modelos e plantas de utilidade comprovada. (BURKE, 2014, p. 81)

Burke elogia o preconceito, que resiste a inovação e a inconstância, como algo que gera resultado positivo a estabilidade da Constituição do país. Para Paulo Henrique Cassimiro (2015), o preconceito a qual Burke se refere não quer dizer juízo discriminatório, mas o senso comum que dá sentido de pertencimento a determinada tradição. Segundo Burke, toda sociedade precisaria de um sistema de costumes que fosse apreciado pelas mentes que a compõem. No caso da tradição europeia, sua base seria o cavalheirismo e a religião crista. Ao defender tal conteúdo da cultura europeia, o autor faz declaração que reafirma a importância da história em seu pensamento: "Estamos demasiado inclinados a considerar as coisas no estado em que as encontramos, sem ponderar suficientemente sobre as causas pelas quais foram produzidas e que devem possivelmente preserválas. " (BURKE, 2014, P. 97). O uso da história em Burke pressupõe uma união indissociável entre o passado e o presente na qual o segundo nada mais é do que um resultado do primeiro. O autor ao dissertar sobre o bom tratamento dado a um 
rei da França derrotado em campo de batalha pela Inglaterra há 400 anos revela sua compreensão de natureza humana comum e conceito de história fixo e não linear: "Embora tenham se passado 400 anos, não creio que tenhamos mudado substancialmente desde então. Graças à nossa tenaz resistência à inovação, à fria indolência de nosso caráter nacional, ainda carregamos a estampa de nossos antepassados. " (BURKE, 2014, p. 105)

Contudo, apesar de sua dura crítica aos iluministas e seu idealismo, há em Burke também certo espaço para uma ideia de progresso a partir de sua noção de aperfeiçoamento. Embora sua visão de história por vezes aparente ser estática e ele afirmar que não existem coisas novas a serem descobertas no campo da moral e dos grandes princípios de governo, Burke aceita que uma monarquia que não é submetida à inspeção de representação popular comete abusos (BURKE, 2014, p. 144). Isso é coerente com a sua defesa do modelo inglês e também indica que há certa ideia de progresso nele, uma vez que esta forma de monarquia é mais evoluída do que sua versão absoluta. A ideia de herança do autor não é mera manutenção do estado atual das coisas, mas sim uma visão reformista da história e da política na qual as mudanças se ancoram em um "[...]princípio seguro de conservação, com um princípio de transmissão e sem excluir um princípio de aperfeiçoamento. (Idem, p. 55). Burke defende um reformismo conservador no qual se conserve as partes boas das instituições e o resto seja adaptado durante um longo período de tempo para, deste modo, o espírito ser preservado. A obra de Burke é sintomática do tipo de concepção da história do iluminismo escocês, centrada na ideia de evolução e emancipação da sociedade civil. Segundo Leo Strauss (1953), a obra de Burke está inserida no historicismo moderno, mas em sua versão romântica e conservadora.

Na visão do autor, a Revolução poderia ter sido evitada e a França poderia ter seguido o aperfeiçoamento das suas instituições tal como fez a Inglaterra. Eles poderiam ter sido facilmente conquistados como concessões do Rei durante as reuniões dos Estados-gerais ou instituições simultâneas. Ele diz que a Constituição britânica é um exemplo de onde isso aconteceu. Os erros da nobreza francesa que teriam causado sua própria queda teriam sido os de favorecer demais os filósofos que causaram sua ruína e o fato de não terem conseguido incorporar os camponeses que alcançaram ou superaram a nobreza em riqueza. Embora defenda que tal grupo não deveria ser tratado como os nobres, Burke critica o fato de eles não terem sido admitidos com a posição social que diria respeito a tal riqueza. Homens de letras, por não serem agregados 
à Corte e por não serem solicitados pelo rei desde Luís XIV compuseram uma corporação própria. Os filósofos tinham interesse distinto do monetário, mas aliado a ele, estes literatos teriam dado justificativa ideológica para o confisco das propriedades eclesiásticas, uma vez que estavam interessados em destruir a fé cristã.

Para Burke a crise econômica da França pré-revolucionária poderia também ter sido resolvida de outra forma que não a revolução e o confisco de propriedades consequente. Taxação modesta cobrada proporcionalmente aos cidadãos é uma das soluções apresentadas. Burke é também profundamente crítico ao confisco de bens da Igreja como forma de sanar a crise econômica. Além de entender que tal medida seria ineficiente, o autor recorre a tradição para defender que o clero francês - principalmente o clero regular - era um segmento social profundamente erudito e condizente com uma boa moral. As instituições monásticas eram incapazes de converter os bens da comunidade em bens privados, elas tinham a pobreza pessoal como honra. $\bigcirc$ autor mobiliza a tentativa de criação de uma república teocrática por anabatistas em Munster na Alemanha no século XVI como exemplo histórico de que um sistema nivelador e que tem "opiniões bárbaras sobre a propriedade" (BURKE, 2014, p. 168) é ineficiente em conseguir seus próprios objetivos. Burke compara o fanatismo dos anabatistas com o fanatismo ateu de sua época.

Toda a crítica feita pelo autor sobre a Constituição da França após a revolução parece ter como tônica o fato de eles serem idealistas na implementação de políticas e não levarem em conta as experiências deixadas pela história, por conta disso, eles teriam errado persistentemente. Para o autor, a Constituição francesa é o simétrico oposto da britânica. Burke segue no texto criticando os fatores aglutinadores da Constituição na França após a revolução, ou seja, os poderes executivo, legislativo e o exército, todos vítimas do esforço revolucionário de impor ao mundo ideias abstratas. A tentativa idealista de transpor modelos aritméticos e geométrico na administração pública, na economia e na política teriam levado a resultados desastrosos. O autor chega a enunciar um dos teóricos reivindicados pelos revolucionários para passar a mensagem de quão delirante ele considerava as políticas adotadas: "Estivesse vivo Rosseau, estou seguro de que ele, em um de seus intervalos de lucidez, ficaria chocado com o delírio prático de seus discípulos, que o imitam servilmente em seus paradoxos e revelam em sua incredulidade uma fé implícita. " (BURKE, 2014, p. 185)

Paulo Henrique Paschoeto Cassimiro explica que Revolução francesa chamou 
atenção de Burke pois ele temia sua expansão na Inglaterra. Isso teria gerado um nacionalismo de fins em Burke no qual: "Contra o direito Universal do Homem Burke reivindicava o direito do homem inglês. Ao racionalismo teórico dos iluministas, Burke contrapunha a razão prática dos ingleses. " (CASSIMIRO, 2015, p. 9). O autor apresenta ainda que para Burke a crítica da revolução vem no sentido de defender a Constituição, sedimentada na tradição histórica. Para Cassimiro (Idem), Edmund Burke é acima de tudo um tradicionalista, por isso são os costumes que dão para ele a validade da sociedade política, entendida como "[...]associação entre vivos mortos e os que irão nascer. " (CASSIMIRO, 2015, p.

12)

\section{Alexis de Tocqueville e o julgamento histórico para o presente}

Alexis de Tocqueville publica sua obra em 1856. Diferente de Edmund Burke, o autor irá refletir sobre os eventos da revolução francesa como algo que não lhe é contemporâneo. Nem por isso sua preocupação ao tratar do tema deixa de ser com o presente. Por conta disso, Tocqueville define seu esforço não como uma história da revolução francesa, mas como um estudo da mesma (TOCQUEVILLE, 2009, p. XLI). Segundo François Hartog (2013) o regime de historicidade teria se modificado a partir da revolução francesa. Na medida em que um modelo de história exemplar já não conseguia mais orientar a ação, surge o conceito moderno de história como progresso e a serviço dele. Se entende então a História no singular, como processo universal.

Para Marcelo Jasmin (1997) o conceito de história de Tocqueville é presentista e pragmático, ou seja, "[...] suas preocupações permaneceram orientadas para a política, o sentido da modernidade e o futuro francês. " (Idem, p. 251). Segundo o mesmo autor, para Tocqueville a maneira como se julga o passado pode ter repercussões no futuro e "[...] por isso, a escrita da história pode ser ela mesma considerada uma ação. " (Ibidem, p.258). Ainda segundo Marcelo Jasmin, a história em Tocqueville teria em si um conteúdo de universalidade, uma vez que o autor francês teria realizado um estudo histórico que visaria ultrapassar uma visão de história enquanto consequência de eventos para propor um conjunto de teorias que servissem para a compreensão geral da política, independentemente do contexto específico na qual surgiram. Marcelo Jasmin conclui então que: "Neste sentido, as conclusões da historiografia tocquevilleana constituem uma ciência política que, embora formulada a partir de uma experiência peculiar, quer 
alcançar a universalidade da abstração teórica. " (JASMIN, 1997, p. 267).

Informado por certa tradição de história enquanto exemplo, que segundo Marcelo Jasmin (1997) remonta a Montesquieu, e por uma filosofia da história consonante com o conceito moderno de história, que neste caso compreende o curso da humanidade em direção a democratização, Alexis de Tocqueville irá compartilhar o diagnóstico de Edmund Burke de que a Revolução Francesa foi um evento evitável e desnecessário no qual se tentou forçar por meio da violência algo que poderia ter sido conquistado por outros meios. No caso de Tocqueville tratava-se de um processo histórico em curso e inevitável. Marcelo Jasmin refere-se ao posicionamento político de Tocqueville como "reformista conservador" (Idem, p. 274), mesma alcunha que pode ser usada para classificar Burke.

O Antigo Regime e a Revolução (TOCQUEVILLE, 2009) se divide em três livros. No primeiro o autor pretende investigar a natureza da Revolução Francesa, no segundo suas causas de longo prazo e no terceiro as causas imediatamente anteriores ao evento. Logo na primeira parte da obra o autor já deixa perceber que para ele a história da França se circunscreve em um processo universal em um mesmo sentido e direção que os Estados modernos do Ocidente. Isso fica claro na sua afirmação de que "[...] quem houver estudado e visto somente a França, ouso dizer que nunca compreenderá coisa alguma da Revolução Francesa. " (TOCQUEVILLE, 2009 p. 22). Posteriormente, o autor confirma sua interpretação de que o evento de 1789 foi desnecessário: "Se não tivesse acontecido, o velho edifício social não teria deixado de cair em todo lugar, aqui mais cedo, ali mais tarde; apenas, teria continuado a cair parte por parte em vez de desmoronar de uma só vez." (Idem, p. 24)

Os resultados da Revolução Francesa seriam produzidos para Tocqueville mais ou menos independentemente dela. Os produtos da democratização eram alcançados também nos Estados Unidos, na Inglaterra, na Alemanha. A perspectiva da igualdade não é uma realidade francesa, mas universal em relação ao mundo cristão, tal como sugere o conceito moderno e linear de história. Assim, de um lado, ele apresenta na abertura do livro a Revolução Francesa como o maior evento da humanidade e a considera, de outro, apenas um episódio do processo de transformação social, ainda que o mais importante. O laço que Tocqueville dá nessa questão é afirmar que a Revolução Francesa torna evidente e manifesta a crise do mundo aristocrático e a emergência da modernidade. A Revolução põe em evidência e acelera a história do advento da Democracia. 
Segundo Marcelo Jasmin (1997), o pensamento de Tocqueville é comparativo em pelo menos dois sentidos: pelo cotejo dos diferentes estágios de cada uma das nações e pela distinção estrutural entre Democracia e Aristocracia, conceitos caros ao autor. Seu estudo mobiliza-se para entender a mudança de um passado para um presente, em pontos diferentes do universo cristão. Mais adiante, o autor afirma que sua preocupação é entender como o paciente poderia salvar-se, ou seja, como o Antigo Regime poderia ter se mantido. Isso indica que Tocqueville não encara a Revolução sob uma perspectiva fatalista, ainda que ela faça parte de um amplo processo invencível.

Tocqueville escreve o segundo capítulo do primeiro livro para defender que o problema da Revolução não era, de modo algum, vencer a religião em si, mas sim o poder e a estrutura criada pela religiosidade. Se é fato que o pensamento revolucionário francês tinha inúmeras marcas irreligiosas, ele seguramente poderia suportar o espírito religioso, como seguiu a tolerar pelos anos seguintes, mas não o poder eclesiástico, inspirado nessa sede não-humana.

A seguir ele compara a Revolução Francesa com uma revolução religiosa, porque ambas tratariam de um sujeito universal, de uma plataforma e de um programa igualmente universais. A Política e as revoluções políticas teriam dito respeito até então sempre às circunstâncias e aos problemas específicos de cada lugar. A Revolução Francesa pareceria religiosa porque falou como a Religião, ou como a Filosofia: dos homens como se fosse $O$ Homem, daquilo que diz respeito a todos, do que é absolutamente válido e verdadeiro a qualquer tempo. A Revolução Francesa foi para Tocqueville uma revolução política que se fez conforme uma revolução religiosa. Nas palavras do autor:
A revolução francesa operou, com relação a este mundo, precisamente do mesmo modo que as revoluções religiosas agem com vistas ao outro; considerou o cidadão de um modo abstrato, apartado de todas as sociedades particulares, assim como as religiões consideram o homem em geral, independentemente do país e da época. Não indagou apenas qual era o direito particular do cidadão francês, mas quais eram os deveres e os direitos gerais do homem em matéria política. (TOCQUEVILLE, 2009. p. 15)

No capítulo seguinte, Tocqueville defende o valor da liberdade política para a igualdade. Ele se recusa a reduzir a liberdade à dimensão exclusivamente econômica, como a própria sociedade teria feito. Cada um deve fazer o que quer, 
desde que isso aconteça na interação política da comunidade. A igualdade sem liberdade seria justamente a forma de despotismo que ele procura afastar, a qual ele intitula de despotismo democrático.

Nos dois outros livros que compõem a obra, o autor segue tratando respectivamente das causas que explicam a Revolução Francesa, as razões para o processo de igualação ter se dado na França como se deu e os motivos para que, apesar de seguir um rito universal da história moderna, a Revolução ter sido tão particular. No segundo livro, o autor se dedica a mostrar continuidades entre o Antigo Regime e o mundo posterior à Revolução. É possível dizer que Tocqueville destaca ali as causas de longo prazo da Democracia, ou seja, a centralização, a tutela administrativa e a igualação das condições sociais dos homens. Sua primeira explicação é que centralização política do Estado Moderno desenvolveu-se paralelamente à centralização administrativa. Todo o povo francês teria passado nesse processo a depender do Estado. Houve uma perda de autonomia por parte das comunas, das entidades rurais, das associações locais. Isso seria prejudicial na medida em que o Estado assume para si toda a tarefa de pensar e fazer o mundo da Política.

Assim como Edmund Burke, Alexis de Tocqueville entende que a Revolução Inglesa fez um percurso contrário. Ela teria sido a imposição da autonomia sobre o poder absoluto. A partir de tal análise do autor pode-se inferir as diferentes formas de democracia concebidas por ele. A igualdade poderia se combinar coma liberdade ou com a servidão, em outras palavras, ou todos têm poder ou ninguém o tem. Os homens podem determinar a si mesmos ou serem todos determinados por outros. Não adianta falar das formas exteriores da liberdade. Tocqueville dá lugar a agência humana nos processos históricos pois compreende que o problema da liberdade para os homens é que eles, e somente eles, podem pensar para si um mundo seu.

Outra explicação do autor é que Revolução foi uma reação da população que não mais suportava os privilégios do Antigo Regime. Na França, a feudalidade teria deixado de ser uma instituição civil e passado a ser uma instituição política. Isso porque a nobreza teria se esvaziado de seus deveres, mas mantido privilégios que despertaram o ódio dos franceses pelas classes dirigentes. Para o autor, a nobreza teria deixado de ser classe para ser casta. Em sua submissão ao poder central, pela centralização da administração e pela sujeição à corte, a nobreza é derrotada pelo abandono de suas funções, abandono esse que ela mesmo se impõe. $\bigcirc$ tecido social do feudalismo teria se rompido, não haveria 
mais solidariedade entre os segmentos sociais. Correlato a isso, os plebeus não recebiam nenhuma contrapartida da aristocracia, mas sim do Estado. Nas palavras de Tocqueville:

Mas quando o burguêsficou assim totalmente isolado do fidalgo, e o camponês do fidalgo e do burguês; quando um trabalho análogo teve prosseguimento no seio de cada classe e formaram-se no interior de cada uma delas pequenas agregações particulares quase tão isoladas umas das outras quanto as classes o eram entre si, sucedeu que o todo formava apenas uma massa homogênea cujas partes porém não estavam interligadas. Agora nada estava organizado para atrapalhar o governo, nada tampouco para auxiliá-lo. De tal modo que o edifício todo da grandeza daqueles príncipes pôde desmoronar por inteiro e em um momento, assim que a sociedade que the servia de base se agitou. (TOCQUEVILLE, 2009, p.148).

Contudo, Tocqueville inova ao apresentar que isso não se deve ao fato do feudalismo francês ser mais hierárquico. Ao contrário disso, a Revolução aconteceu justamente onde a igualdade entre nobres e plebeus era maior e onde a consistência dos direitos feudais era menor. Foram as camadas mais livres do feudalismo que se levantaram. Não foram os servos mais explorados da Alemanha e Inglaterra que se engajaram em um movimento revolucionário, mas os camponeses livres e proprietários da França. Para Tocqueville, um movimento revolucionário não se faz em um momento de crise extrema, mas sim quando há uma melhora, que expande em muito a expectativa e os interesses dos demais segmentos sociais. A melhoria faz com os homens encarem as velhas formalidades e tradições como não naturais, vencíveis e vencidas. Quanto mais a servidão afrouxa, menos se impõe ou faz sentido. Para o servo o seu mundo seria tal como lhe parece, para o camponês que se liberta, qualquer resquício de sua condição anterior seria pavoroso.

No terceiro livro, Alexis de Tocqueville tenta chamar a atenção do leitor para a imprudência dos atores políticos que eram responsáveis pela Monarquia. Nos anos anteriores a 1789, ministros e administradores de Estado teriam tomado medidas temerárias que acabaram por levar ao descontentamento cada vez maior dos populares. A insatisfação francesa teria então tomado uma forma literária. A crítica teria se manifestado por um espírito filosófico e abstrato. Não se pensavam e expressavam diretamente os problemas específicos das instituições 
monárquicas, mas indiretamente, a partir das questões reflexivas sobre o homem, a vida, os direitos e a Política. O espírito literário idealista caracterizase por pensar um mundo completamente novo, para substituir por inteiro o antigo, tal como a tábula rasa criticada por Burke. A questão é que também a novidade quando realizada iria enfrentar seus problemas concretos, obrigando que o espírito retorne a crítica e volte a elaborar um novo mundo. Para o autor esse espírito explica as fases da Revolução francesa, elas teriam sido revoluções seguidas, uma dentro da outra.

A França seria entre as nações da Europa a mais ligada à literatura. Apesar disso, seus homens de letras deixaram o isolamento e se aproximaram das atividades públicas, de onde estavam o mais afastado possível. Eles se tornaram uma espécie de vanguarda da política, sem que a conhecessem em seu cotidiano e andamento, ou seja, careciam da experiência tão valorizada por Burke para o agir político. Para o autor, as leis gerais do pensamento não seriam capazes de resolver o mundo, mas sim de lhe criar novos problemas. A abstração não seria suficiente para a sociedade justamente porque a segunda funciona no concreto. Ademais, instituições idealizadas seriam desprovidas de experiência.

Não só para Burke, mas também para Tocqueville não se teria produzido na França uma conexão entre o sistema político e a experiência da política. Quando se aniquila o mundo real para colocar em seu lugar uma ordem pensada pela Razão, a sociedade não poderia vingar em realidade. A tentativa de matematizar o mundo dos homens seria sempre um fracasso, porque o mundo dos homens se caracterizaria justamente por não ser matematizável. Assim como Burke, Tocqueville distingue a via idealista realizada na França da via ligada a experiência realizada na Inglaterra:

Enquanto na Inglaterra os que escreviam sobre o governo e os que governavam estavam juntos, uns introduzidos na prática as ideias novas e os outros retificando e circunscrevendo as teorias por meio dos fatos, na França o mundo político permaneceu como que dividido em duas províncias separadas e sem contato entre si. Na primeira administrava-se; na outra estabeleciam-se os princípios abstratos nos quais toda a administração deveria fundamentar-se. Aqui se tomavam medidas particulares que a rotina indicava; lá proclamavam-se leis gerais, sem nunca pensar nos meios de aplica-las; para uns, a condução dos assuntos; para outros, a direção das inteligências. (TOCQUEVILLE, 2009, p. 161). 
Tocqueville não quer desprezar os pensadores, mas dizer que o Estado e as atividades públicas eram para eles coisas invisíveis. $\bigcirc$ que o autor faz aqui é justificar sociológica e historicamente a existência desses pensadores, pois quando se quis pensar publicamente a política, esses homens só contavam com princípios abstratos, pois não a conheciam em concreto. A multidão teria aceitado esse idealismo porque ignorava ainda mais a realidade política. Explica Tocqueville que os populares jamais se entregariam aos letrados se os franceses ainda participassem do governo. A constatação é que não havia para os homens da França outra via de participação.

\section{Considerações finais: $O$ impacto da crítica historicista da revolução francesa na Historiografia do Século XX}

Dada as comemorações de bicentenário da Revolução francesa, o historiador François Furet publica o livro Pensando a Revolução Francesa (FURET, 1989). Dentro do livro há um capítulo intitulado "A Revolução Francesa terminou", nele o autor polemiza com a historiografia predominante na época. Para o historiador seria problemático o fato de estudar a Revolução Francesa implicar tão diretamente em uma tomada de posição política. Se o lugar político do historiador necessitava de um posicionamento acerca do valor da violência revolucionária, do jacobinismo e do lluminismo, o marxismo então muito presente na historiografia francesa ainda imputava o agravante de pensar 1789 sempre em relação a 1917. Para Furet isso partiria de uma leitura etapista da história na qual o primeiro evento seria a revolução burguesa percussora da revolução socialista.

A consequência direta disso para a historiografia teria sido que o processo não foi visto mais pelas suas especificidades. Além disso, a análise da política e suas representações e ideias teria sido posta em segundo plano em relação a análises econômicas e sócias, uma vez que as primeiras eram entendidas como superestruturais. Furet discorda disso e explica que as ideias políticas não são falsa consciência e sim algo real em si mesmo. Estudar história - incluindo a história da revolução francesa - seria também estudar as representações que ela faz de si.

O título do capítulo é particularmente provocador para as tendências hegemônicas da historiografia de sua época, uma vez que o ano de publicação do livro coincide com a queda do muro de Berlim, o que levou a ruptura do horizonte de expectativas socialista compartilhado por muitos dos historiadores marxistas. 
François Furet parte da tradição crítica deixada por Edmundo Burke e Alexis de Tocqueville e apresenta que a revolução francesa implicou na radicalização que foi tônica do mundo contemporâneo. Do terror jacobino até 1917 o que teria ocorrido foi a tentativa de impor ao mundo a concepção idealista que ganhara forma em 1789. A ideia de revolução como ruptura radical com a ordem já era criticada por Burke e Tocqueville por seu idealismo e consequente compreensão de que é possível transformar o mundo como se ele fosse tábula rasa. Furet partirá da mesma interpretação para explicar que desta concepção de revolução decorreu uma violência desenfreada causada por uma intepretação da realidade herdada dos revolucionários franceses. A Revolução francesa teria terminado em 1989 porque a promessa deixada por ela teve fim, logo, o processo até então em aberto teria se fechado.

A tradição de pensamento da qual Edmund Burke foi espécie de eco quase imediato e na qual Alexis de Tocqueville foi repercussão posterior deu frutos no decorrer do tempo. Se colocando como herdeiro de Tocqueville, François Furet e a tradição de pensamento historiográfico que segue depois dele recuperam por uma via política similar aos seus antecessores a crítica ao idealismo da Revolução francesa. Ao mesmo tempo, tal tradição permanece deixando em aberto a possibilidade da história como instrumento de interpretação da política e do presente em geral, seja pela via que for.

Referências bibliográficas

ARENDT, Hannah. Sobre a revolução. Tradução de Denise Bottman. São Paulo: Companhia das letras, 2011.

BURKE, Edmund. Reflexões sobre a revolução na França. Tradução de José Miguel Nanni Soares. São Paulo: Edipro, 2014.

CASSIMIRO, Paulo Henrique Paschoeto. A história contra a revolução: Edmund Burke e o problema do direito natural. Tempo de Conquista, n. 17, p.1-22, 2015.

FURET, François. Pensando a Revolução Francesa. São Paulo: Paz e Terra, 1989.

HARTOG, François. Regimes de historicidade: presenteísmo e experiências de 
A história como crítica do presente, pp. 119 - 135

tempo. Tradução de André Souza de Menezes, Bruna Beffart, Camila Rocha de Moraes, Maria Cristina de Alencar Silva e Maria Helena Martins. Belo Horizonte: Autêntica, 2013.

JASMIN, Marcelo Gantus. Alexis de Tocqueville: a historiografia como ciência da política. Rio de Janeiro: Acces, 1997.

KOSELLECK, Reinnhart; MEIER, Chrisrtian; GUNTHER, Horst; ENGELS, Odilo. O conceito de história. Tradução de René Gertz. Belo Horizonte: Autêntica, 2013.

MANNHEIM, Karl. O pensamento conservador. In: MARTINS, José de Souza (Org.). Introdução à Sociologia Rural. São Paulo, 1981.

STRAUSS, Leo. Natural Right and History. Chicago: Chicago press, 1953.

TOCQUEVILLE, Alexis de. O antigo regime e a revolução. Tradução de Rosemary Abílio. São Paulo: Martins Fontes, 2009. 